
J. Boldt
M. Müller
D. Mentges
M. Papsdorf
G. Hempelmann

\section{Retraction Note: Volume therapy in the critically ill: is there a difference?}

Published online: 23 November 2013

(C) Springer-Verlag Berlin Heidelberg and ESICM 2013

The online version of the original article can be found under doi:10.1007/s001340050511.

J. Boldt $(\bowtie) \cdot$ D. Mentges

Department of Anesthesiology and Intensive Care Medicine, Klinikum der Stadt Ludwigshafen, Bremserstrasse 79,

D-67063 Ludwigshafen, Germany

Fax: +49-(621)-50330-24

M. Müller · M. Papsdorf · G. Hempelmann Department of Anesthesiology and Intensive Care Medicine, Justus-Liebig-University Giessen, Giessen, Germany

\section{Retraction to: Intensive Care Med (1998) 24:28-36 DOI 10.1007/s001340050511}

The ethics committee at the University of Giessen was approached to verify whether the study described in this article was submitted there for approval. No records prior to 1993 are available due to the terms of the German Data Protection Act, and there is no trace of study approval between 1993 and 1998 (the year of publication). Therefore, approval of the study can be neither confirmed nor denied. With all due consideration, the Editor-inChief of Intensive Care Medicine has decided to take the precaution of retracting this article. 